\title{
Formulation and Evaluation of Okra Extract Containing Low Foam Producing Shampoo
}

\author{
Nikhil Nagesh Malji, Karuna Vilas Mane, Mayuri Umakant Manthen, Snehal Sangappa Mhamane
}

Student, D.S.T.S. Mandal's College of Pharmacy, Solapur, Maharashtra, India

\begin{abstract}
How to cite this paper: Nikhil Nagesh Malji | Karuna Vilas Mane | Mayuri Umakant Manthen | Snehal Sangappa Mhamane "Formulation and Evaluation of Okra Extract Containing Low Foam Producing Shampoo" Published in International Journal of Trend in Scientific Research and Development (ijtsrd), ISSN: 24566470, Volume-3 | Issue-4, June 2019, pp.174-176, URL: https://www.ijtsrd.c om/papers/ijtsrd23 619.pdf

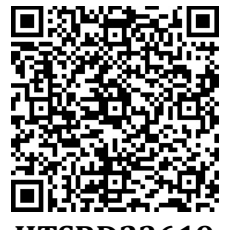

IITSRD23619

Copyright (C) 2019 by author(s) and International Journal of Trend in Scientific Research and Development Journal. This is an Open Access article distributed under the terms of the Creative Commons

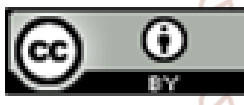
Attribution License (CC BY 4.0) (http://creativecommons.org/licenses/ by $/ 4.0$
\end{abstract}

Description: Biological name: Hibiscus esculentus, Abelmoschus esculentus.

\begin{abstract}
Scientific classification:
Kingdom: Plantae

Division: Magnoliophyta Class: Magnoliopsida

Order: Malvales

Family: Malvaceae

Genus: Abelmoschus

Species: A.Esculentus
\end{abstract}

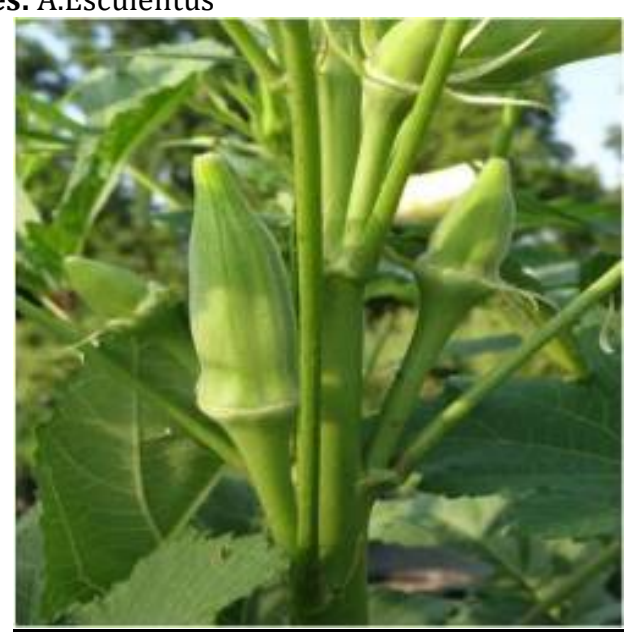

ABSTRACT

The main aim of the preparation of hair shampoo is for the hair care. It is aim principle in the cleansing of hair. To assess its physiochemical function that emphasis on safety, efficacy, eliminating harmful synthetic ingredients. The safety of hair shampoo is established by selection of safe natural material.

KEYWORDS: Okra extract, shampoo, low detergency, hair care.

\section{INTRODUCTION TO OKRA:}

Okra (Abelmoschus esculentus) is the only vegetable crop of significance in the Malvaceae family and is very popular in the Indo-Pak subcontinent. In India, it ranks number one in its consumption but its original home is Ethiopia and Sudan, the north-eastern African countries. It is one of the oldest cultivated crops and presently grown in many countries and is widely distributed from Africa to Asia, southern Europe and America. It is a tropical to subtropical crop and is sensitive to frost; low temperature, water logging and drought conditions, and the cultivation from different countries have certain adapted distinguishing characteristics specific to the country to which they belong1. It is an oligo purpose crop, but it is usually consumed for its green tender fruits as a vegetable in a variety of ways. These fruits are rich in vitamins, calcium, potassium and other mineral matters. The mature okra seed is a good source of oil and protein has been known to have superior nutritional quality. Okra seed oil is rich in unsaturated fatty acids such as linoleic acid, which is essential for human nutrition. (5)

\section{INTRODUCTION:}

Shampoos are kind of formulation that are used for hair and body washing or therapeutic purposes. Shampoos are expected to be much more than mere cleansing agents. Shampoos have many properties in addition of their detergency, such as conditioning and hair shining. They are expected to be non-irritating to skin and mucous membranes. There are many different varieties of ingredients for making a proper shampoo. Each of these ingredients have special role in shampoo's formulation. The major ingredients used in making a shampoo are detergents (surfactants), conditioning and active ingredients for hair manageability, additives that modify the surfactant effect (viscosity control agents, foam stabilizers and viscosity modifiers), stabilize the product (preservatives and antioxidants) and increase its appeal (fragrances, essence, antiUV light protector, dyes and ingredients for consistency and a pearlescent appearance). Some of these additives are arbitrary while many of them have to be added in a shampoo formulation to increase its stability and safety Conditioning agents are examples of these additives. They have been attractive components in the recent years. Surfactants are specific conditioners but there are many other materials used as conditioners, such as paraffin and lanolin. There are also many other materials that serves as conditioners like peptides, egg derivatives and synthetic resin. These 
materials were added in shampoo formulation as hair conditioner and hair shining agents. Other polymers used in the formulation of shampoos that are capable of drawing crisp hair could be water soluble phosphate salts and amino ethyl ester poly acrylic acid. The resin is used in the formulation of shampoos containing surfactants. Water soluble proteins, such as hydrolyzed collagen with molecular weight between 500 to 10,000 Dalton and their tetravalent derivatives cause improve in the ease of wet and dry hair combing. These compounds have protective effects for hair and make them softened and possible stimulatory effects of shampoos. This combination causes hair softening and gives hair status like silk mode. In order to smooth the hair and make them glow the oily materials called super fatty materials are used.

\section{Types of Shampoo:}

Powder Shampoo, Liquid Shampoo, Lotion Shampoo, Cream Shampoo, Jelly Shampoo, Aerosol Shampoo, and

\section{Specialized Shampoo-}

-Conditioning Shampoo •Anti-dandruff Shampoo •Baby Shampoo •Two Layer Shampoo

\section{Objective:}

To develop the most effective hair care product to meet patient compliance. To evaluate the prepared hair care product to establish desired effect on patient. The objective of hair Shampoo is to clear the dirty hair and give them shiny effect.

\section{MATERIALS:}

Fresh immature pods of Okra were collected from local market. The pods were washed thoroughly with sterile distilled water and seeds were separated from the pods, dried and pulverized to fine powder using grinder.

\section{PREPRATION OF EXTRACTION:}

For extraction about 50 grams of the ground seed was dissolved in $100 \mathrm{ml}$ of sterile water and left for $48 \mathrm{~h}$ at room temperature. After $48 \mathrm{~h}$, the mixture was filtered using clean muslin cloth and the filtrate was used for formulation.

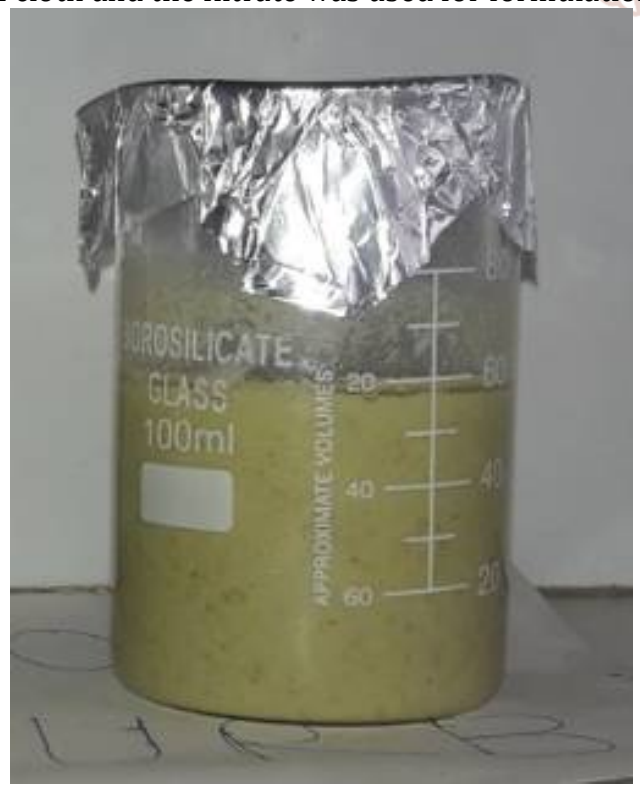

\section{CONFIRMATION OF SAPONIN:}

Small amount of extract is taken and little quantity of water is added and vigorously stirred.

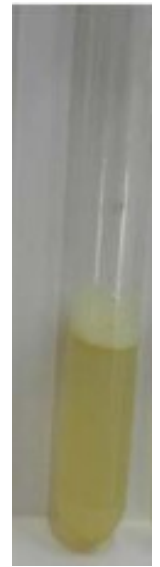

FORMULA: (1) (4)

\begin{tabular}{|c|c|c|}
\hline SR. NO & INGREDIENTS & QUANTITY FOR $100 \mathrm{ml}$ \\
\hline 1 & SLS & $20 \mathrm{ml}$ \\
\hline 2 & Glycerin & $8 \mathrm{ml}$ \\
\hline 3 & Seed extract & $50 \mathrm{ml}$ \\
\hline 4 & Aloevera gel & $9.5 \mathrm{ml}$ \\
\hline 5 & Vitamin E oil & $2 \mathrm{ml}$ \\
\hline 6 & Carbapol 940 & $0.3 \mathrm{gm}$ \\
\hline 7 & Triethanolamine & $0.2 \mathrm{gm}$ \\
\hline 8 & Water & $10 \mathrm{ml}$ \\
\hline
\end{tabular}

PROCEDURE: (1) (4)

Measure a small quantity of water, and then add Carbapol and triethanolamine. Then add required quantity of Aloevera gel and vitamin E oil and stir properly and add aqueous seed extract into the mixture. Then SLS solution is added and mixed properly to get the shampoo.

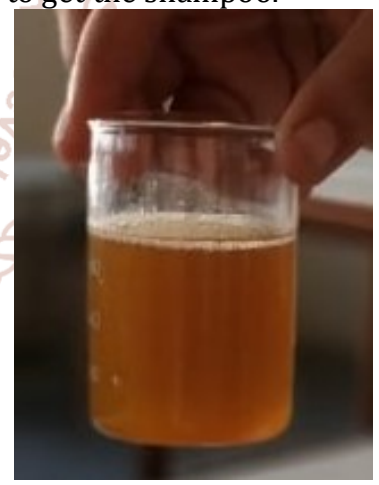

EVALUATION PARAMETERS:

$>$ Product Characteristics:

1. Colour- Orange colour.

2. Fragrance- orange.

3. Consistency- Good, no grittiness

pH:

The $\mathrm{pH}$ was determined by using digital $\mathrm{pH}$ meter and the $\mathrm{pH}$ of herbal hand wash was found 6 .

\section{Foam productivity determination:}

$10 \mathrm{ml}$ of shampoo was stirred with glass rod a certain speed in a graduated cylinder for $2 \mathrm{~min}$. volume of foam produced was measured.

\section{Viscosity:}

The viscosity of shampoo was determined by using digital Brookfield viscometer. Measured quantity of shampoo was taken into a beaker and the tip of viscometer was immersed into it and the viscosity was measured in triplicate. 


\section{$>$ Stability:}

The stability studies were carried out by storing at different temperature conditions like $40^{\circ} \mathrm{C}, 25^{\circ} \mathrm{C} \& 37^{\circ} \mathrm{C}$ for 4 weeks. During the stability studies no change in color and no phase separation were observed in the formulated shampoo.

\section{Irritancy test:}

After using the shampoo no irritation was observed.

\section{RESULT AND DISCUSION:}

Shampoo was formulated by using aqueous extract of seeds of okra. Seeds contain phytochemicals such as saponins which are natural surfactant possessing good detergency and foaming properties. A good shampoo must have adequate viscosity facilitate removal from the bottle but must not drip from the hair during use.

\section{CONCLUSION:}

The present study aimed to prepare a stable, self preserved a shampoo formulation contains low detergent to reduce the risk of chemicals. Results showed that no significant difference between the prepared and marketed product.
However these formula contains less detergent content as the reference that make them in favorite on commercial product. We formulated a shampoo by using seed extract of okra. All the ingredients used to formulate are safer than silicones.

\section{REFERENCES:}

[1] Text book of Cosmetics by M.Vimaladevi professor Pharmaceutical Technology, Andhra University, Visakhapatnam, 1st edition 2005 page no. 153- 156.

[2] Kokate CK, Purohit AP, Gokhle SB, "Pharmacognosy", 42 ${ }^{\text {nd }}$ Edition Nirali Prakashan, 2008.

[3] Khandelwal KR, Practical Pharmacognosy Techniques and Experiment, 19th edition Nirali Prakashan, 2008.

[4] Modern Cosmetics, a Practical Handbook formulation and Production of cosmetics by E.G. Thomson.

[5] D. Sathish kumar, A REVIEW ON: ABELMOSCHUS ESCULENTUS (OKRA) International Research Journal of Pharmaceutical and Applied Sciences, Page no. 129-130.

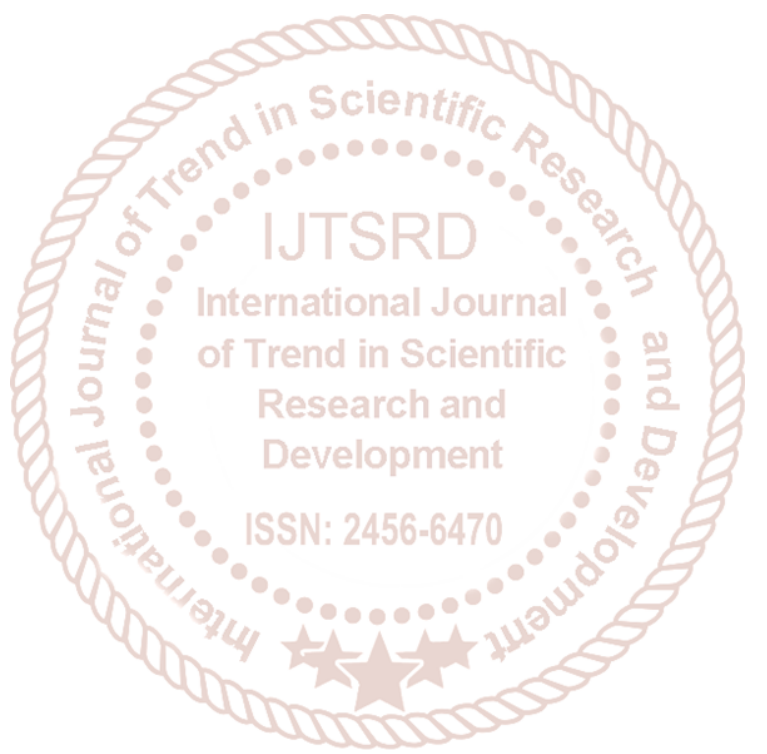

